\title{
Study on the Evaluation of Construction Company Efficiency Based on GRA and DEA

\author{
Yan Chang ${ }^{\text {a }}$, Fuzhou Luo
}

School of Management,Xi' an University of Architecture and Technology,Xi'an 710055,China

a1056678450@qq.com

Keywords: Construction efficiency,Comprehensive efficiency,Data envelopment analysis,Gray relational analysis.

Abstract. Based on 30 listed construction companies input-output data for the study, establish index of construction input and output in construction companies, first use gray correlation analysis to screen indicators, and then use data envelopment analysis method to evaluate 30 efficiency of construction companies. The results showed that the comprehensive efficiency and technical efficiency are high,and scale efficiency is the key to restrict its production efficiency.

\section{Introduction}

The construction industry is one of the pillar industries of the national economy,the construction companies are as the main sector of construction industry, their efficiency level is closely related with the healthy and sustainable development of the construction industry. Therefore, it is necessary to choose an effective evaluation method for building a evaluation of the efficiency, and based on the results to improve their productivity and enhance their competitiveness.

Building business efficiency has been the focus of attention of scholars in Construction industry. Horta and other people use two methods of Efficiency DEA to evaluate Portuguese construction companies and propose an appropriate competitive strategy[1]. Chen Ping,Wu Zongfa evaluate listed buildings studied with the PCA-DEA and PCA-SFA, and make recommendations on how to improve efficiency [2].Wang Yousong and other people evaluate six provinces in South China construction companies with ultra-efficient DEA efficiency evaluation carried out, and the 2007 and 2011 results were longitudinal comparison[3]. In a word,first we should establish input and output indicators and then to evaluate the efficiency of construction companies.

\section{Model}

GRA model establishment. The basic idea is that gray correlation analysis: factors in gray system with time and the reference object changing divided into two categories namely a reference sequence and comparison of sequences. Both their changing trends of consensus sequences can be vividly represented by two curves, the higher degree of similarity curve, their relative variation on the basic agreement, the greater degree of correlation between them, resulting in deciding which are the main factors, which are unnecessary secondary factor. GRA model specific steps are as follows:

(1) processing of the raw data.The commonly used method is initial value method, average method and interval method, we use the average method. Which is: $X_{i}=\frac{X_{i}}{\bar{x}}$

(2)Calculate the correlation coefficient. The correlation coefficient is:

$$
r_{0 i}(\mathrm{k})=\frac{\min _{i} \min _{k}\left|X_{o}(k)-X_{i}(k)\right|+\rho \max _{i} \max _{k}\left|X_{o}(k)-X_{i}(k)\right|}{\left|X_{o}(k)-X_{i}(k)\right|+\rho \max _{i} \max _{k}\left|X_{o}(k)-X_{i}(k)\right|}
$$

In (2) equation, $\rho$ represent coefficient indicates resolution,generally take 0.5.

(2) Calculate the gray associated degree. 
$\Gamma_{0 i}=\frac{1}{n} \sum_{k=1}^{n} r_{o i}(k), \mathrm{i}=1,2, \ldots, \mathrm{m}$

This study rules that: $r_{o i} \geq 0.7$ indicates that index $\mathrm{i}$ and the reference index have significant correlation, it should be identified as the index; if $r_{o i} \geq 0.6$, consider the actual to decide it should be selected;if $r_{o i}<0.6$, shows that the index should be removed .

DEA model establishment.Data envelopment analysis is to evaluate the relative effectiveness of departments or units with multiple inputs and multiple outputs, using mathematical programming models, according to the data obtained DMU determine whether it is valid DEA and its essence is to determine DMU is located in the set of production frontier.DEA model specific steps are as follows:

Suppose to evaluate the efficiency of $\mathrm{k}$ individual construction companies, which each company respectively have $\mathrm{l}$ and $\mathrm{m}$ input indicators and output indicators , the model is:

$$
\left\{\begin{array}{l}
\min \theta \\
\text { s.t. } \sum_{i=1}^{k} \lambda_{i} X_{i j}+S_{j}^{-}=\theta X_{i j} \\
\sum_{i=1}^{k} \lambda_{i} y_{i r}+S_{r}^{+}=y_{i r} \\
\sum_{i=1}^{k} \lambda_{i}=1 \\
\lambda_{i} \geq 0, i \neq 0
\end{array}\right.
$$

In the above formula, $\theta$ refers to comprehensive efficiency index; $\lambda_{i}$ is the input and output indicators corresponding weight coefficient; $X_{i j}$ indicates the i-th evaluation object's j-th input index value, $y_{i r}$ indicates i-th evaluation object's r-th output index value; $S_{j}^{-} 、 S_{r}^{+}$respectively refer to the slack variables of input and output,represent redundant input and less output. Comprehensive efficiency (TE) can be decomposed into pure technical efficiency (PTE) and scale efficiency (SE), the relationship of them can be expressed as: TE $=$ PTE $*$ SE. PTE reflects the use of its resources for a given investment, the ability to obtain the maximum output; SE is reflected whether operate in the most appropriate scale of investment resources. If $\theta<1$, it means that the DMU is not valid, that does not make inputs into the largest production. When the PTE $=1, \mathrm{SE}=1$, represents PTE and SE of the construction companies are optimal to achieve DEA effective.

\section{Empirical Research}

3.1 Index of construction companies efficiency evaluation system based on GRA

(1) index selection

Read through the relevant literature, the investment indicators of construction company efficiency include: total assets, net fixed assets, main business cost, number of employees, net worth of machinery and equipment and so on; output indicators include: the total profit, total revenue, the main business income, labor productivity and so on.

(2) GRA model analysis

Use GM software to carry on gray relational analysis and the results are shown in Table 1 
Table 1 Index relational analysis of construction enterprises efficiency evaluation

Main business income Total profit Total revenue Labor productivity $Y_{1}$ $\mathrm{Y}_{2}$ $\mathrm{Y}_{3}$ $\mathrm{Y}_{4}$

\begin{tabular}{lllll}
\hline Total assets $\mathrm{X}_{1}$ & 0.92 & 0.83 & 0.84 & 0.61 \\
Net fixed assets $\mathrm{X}_{2}$ & 0.65 & 0.64 & 0.69 & 0.67 \\
${\text { Main business cost } \mathrm{X}_{3}}$ & 0.53 & 0.56 & 0.62 & 0.55 \\
${\text { Employee number } \mathrm{X}_{4}}$ & 0.8 & 0.9 & 0.67 & 0.59 \\
${\text { Machinery net worth } \mathrm{X}_{5}}^{0.91}$ & 0.88 & 0.58 & 0.63 \\
\hline
\end{tabular}

As can be seen from the table, investment indicator net fixed assets $\left(\mathrm{X}_{2}\right)$ and output indicators of main business income $\left(\mathrm{Y}_{1}\right)$, the total profit $\left(\mathrm{Y}_{2}\right)$, total revenue $\left(\mathrm{Y}_{3}\right)$, labor productivity $\left(\mathrm{Y}_{4}\right)$ were associated with the degree of mean, $0.65,0.64,0.69,0.67$, although correlation value is greater than 0.6 , but compared with the other indexes, the gap significantly, combined with the actual situation of the study, the net value of fixed assets $\left(\mathrm{X}_{2}\right)$ is removed. Similarly, input indicator the main business cost $\left(\mathrm{X}_{3}\right)$ and output indicators total revenue $\left(\mathrm{Y}_{3}\right)$, labor productivity $\left(\mathrm{Y}_{4}\right)$ should also be excluded. The input index the total assets $\left(\mathrm{X}_{1}\right)$, employees $\left(\mathrm{X}_{4}\right)$, machinery and equipment net $\left(\mathrm{X}_{5}\right)$ and output indicators of main business income $\left(\mathrm{Y}_{1}\right)$, the total profit $\left(\mathrm{Y}_{2}\right)$, Correlation values are greater than 0.7 , indicating significant correlation, so make up the final study indicators.

3.2 DEA-based building enterprise efficiency analysis

Use DEAP2.1 software for data analysis, results shown in Table 2:

Table 2 Input-output efficiency of construction enterprises analysis

\begin{tabular}{ccccc|ccccc}
\hline DMU & TE & PTE & SE & RTS & DMU & TE & PTE & SE & RTS \\
\hline 1 & 0.666 & 0.969 & 0.687 & drs & 16 & 0.852 & 0.984 & 0.866 & drs \\
2 & 0.912 & 1.000 & 0.912 & drs & 17 & 0.852 & 1.000 & 0.852 & drs \\
3 & 0.470 & 0.885 & 0.531 & drs & 18 & 0.834 & 1.000 & 0.834 & drs \\
4 & 0.756 & 0.822 & 0.920 & drs & 19 & 0.840 & 1.000 & 0.840 & drs \\
5 & 0.582 & 0.949 & 0.614 & drs & 20 & 0.803 & 1.000 & 0.803 & drs \\
6 & 0.659 & 0.953 & 0.692 & drs & 21 & 0.726 & 0.992 & 0.732 & drs \\
7 & 0.843 & 0.844 & 1.000 & - & 22 & 0.914 & 1.000 & 0.914 & drs \\
8 & 0.719 & 0.983 & 0.732 & drs & 23 & 0.900 & 0.999 & 0.901 & drs \\
9 & 0.727 & 0.992 & 0.733 & drs & 24 & 0.753 & 0.999 & 0.754 & drs \\
10 & 0.847 & 0.999 & 0.847 & drs & 25 & 0.897 & 1.000 & 0.897 & drs \\
11 & 0.872 & 0.872 & 1.000 & - & 26 & 1.000 & 1.000 & 1.000 & - \\
12 & 0.884 & 0.971 & 0.910 & irs & 27 & 0.999 & 1.000 & 0.999 & drs \\
13 & 0.824 & 0.983 & 0.838 & drs & 28 & 0.845 & 1.000 & 0.845 & drs \\
14 & 0.835 & 0.835 & 1.000 & - & 29 & 0.897 & 1.000 & 0.897 & irs \\
15 & 0.367 & 0.920 & 0.399 & drs & 30 & 0.887 & 1.000 & 0.887 & irs \\
\hline
\end{tabular}

Notes: (1) DMU on behalf of each company number; (2) RTS refers to the scale reward, which, "irs" refers to the scale of diminishing returns, "drs" is on behalf of increasing returns to scale, "-" represents a constant returns to scale. 
In the selected 30 construction companies, the average of comprehensive efficiency is 0.799 , so the efficiency of construction companies is relatively high. Among them, 12 companies,the pure technical efficiency is 1 , accounted for $40 \%$ of the total, indicating that the ability of these enterprises to make full use of resources has reached the optimal level. The mean scale efficiency is 0.828 , and there is 4 companies that scale efficiency is 1 , accounting for $13.34 \%$ of the total, a little low compared with technical efficiency, indicating that the level of resources for investment in these enterprises has reached optimum. Among30 construction companies, increasing scale reward are three, accounted for $10 \%$ of the total, decreasing scale reward are 23 , accounting for $76.67 \%$ of the total, and constant scale reward have four, accounting for $13.33 \%$ of the total .

\section{Conclusion}

In this paper, use GRA-DEA model for evaluating construction companies efficiency , and with the empirical analysis shows that the use of GRA-DEA model can filter indexes, weed out the less relevant indicators, and on this basis research on building enterprise efficiency evaluation, so that the entire study is objective, reasonable and realistic. Practice shows that use GRA -DEA model to evaluate the efficiency of the construction companies, can provide a wealth of information, and provide the basis for improving building enterprise efficiency.

\section{Acknowledgement}

This study is supported by Ministry of Housing and Urban-Rural Science and Technology Project named Development of Real Estate Market in West Resources Cities :Difficulties,Reasons and Countermeasures--Ordos, Yulin Case(2015R4005).

\section{References}

[1] Horta, Camanho, Costa. Performance assessment of construction companies integrating key performance indicators and Data Envelopment Analysis[J]. Journal of Construction Engineering and Management, 2010, 136(5):77-81.

[2] Chen Ping, Wu Zongfa. Business efficiency of our listed building study. [J]. Economic Forum, 2014(12):90-94.

[3] Wang Yousong, Li Chengyao, Zhang Yufan, Research on the efficiency of the construction industry in South China's six provinces based on super efficiency DEA [J]. Construction Industry, 2014(4):19-22. 